\title{
Lumbar Extradural Pseudogout Mass Manifesting as Radiculopathy: A Case Report
}

\author{
Po-Cheng Lo (iD) \\ Chung-Tai Yue ${ }^{2}$ \\ Woon-Man Kung $\mathbb{D}^{3}$
}

'Department of Surgery, Taipei Tzu Chi Hospital, Buddhist Tzu Chi Medical Foundation, New Taipei City, 23/42, Taiwan; ${ }^{2}$ Department of Anatomic Pathology, Taipei Tzu Chi Hospital, Buddhist Tzu Chi Medical Foundation, New Taipei City, 23I42, Taiwan; ${ }^{3}$ Division of Neurosurgery, Department of Surgery, Taipei Tzu Chi Hospital, Buddhist Tzu Chi Medical Foundation, New Taipei City, 23।42, Taiwan
Correspondence: Woon-Man Kung Division of Neurosurgery, Department of Surgery, Taipei Tzu Chi Hospital, Buddhist Tzu Chi Medical Foundation, No 289 Jianguo Road, Xindian District, New Taipei City, 23142, Taiwan

Email nskungwm@yahoo.com.tw
Background: Calcium pyrophosphate dihydrate (CPPD) disease, also known as pyrophosphate arthropathy or pseudogout, is defined as CPPD deposition within the articular cartilage. It was first described in 1962. The representative locations where CPPD disease occurs include the most common knee joint, followed by the wrist joint. Joint swelling and pain are the most common clinical presentations, and the typical differential diagnosis is degenerative arthritis. Microscopically, the specimen demonstrates numerous positively birefringent rhomboid shaped crystals when examined under polarized light.

Case Report: We present a 70-year-old female with right painful sciatica accompanied by coexisting affected limb soreness and clumsiness. Her final diagnosis was unusual lumbar extradural tumoral pseudogout that was worth noticing. Tumoral CPPD deposition was excised after laminectomy. Subsequently, her symptoms were abated postoperatively without a need for more analgesics. Her neurological function was properly recovered.

Conclusion: This is a rare report to proffer pseudogout in an unfamiliar lumbar extradural location, which is an unexpected diagnosis. Making a precise tentative diagnosis for the ongoing disease entity might be difficult for the clinicians because the clinical manifestations of this pathology are similar to those of other common degenerative lumbar spinal diseases. Keywords: calcium pyrophosphate dihydrate, sciatica, lumbar extradural tumor, birefringent crystals, polarized light microscopy

\section{Background}

Calcium pyrophosphate dihydrate (CPPD) deposition typically refers to an inflammatory arthropathy of the peripheral joints, better known as pseudogout. Nevertheless, neurological symptoms caused by the accumulation of these crystals inside the spinal canal are relatively uncommon. ${ }^{1}$ In 2011, the European League Against Rheumatism (EULAR) proposed a standardized terminology to the clinical presentation that acute CPPD crystal arthritis is synovitis in the setting of CPPD. ${ }^{2}$ Acute CPP crystal arthritis (or pseudogout) is the most widely known form of CPPD. Patients usually present with acute attacks of single-joint or oligo-joint arthritis. The knee joint is the most commonly affected joint, followed by the wrist joint. Systemic symptoms include fever, chills, and general malaise, which often occur with acute CPP crystal arthritis. Most patients with chronic CPPD arthritis have a polyarticular form of arthritis similar to degenerative arthritis. A small number of patients will show signs of polyarthritis similar to rheumatoid arthritis but less symmetry. ${ }^{3}$ Crystalline synovial fluid analysis is a simple procedure. With proper training, it is best to use freshly aspirated synovial fluid for examination within 24 hours to make a clear diagnosis of gout and CPPD arthritis. ${ }^{4,5}$ Twelve cases of pseudogout within the lumbar spinal canal have been 
presented in patients from 1991 to 2021 (Table 1). We report our unique case that was initially misdiagnosed as acute right sciatica, and eventually diagnosed as a pseudogout outgrowth located in the lumbar vertebral canal. Although rare, clinicians should be aware of neurological symptoms such as radiculopathy as a result of CPPD deposition compromising the neural elements as a possible differential diagnosis.

\section{Case Report}

A 70-year-old female visited our neurosurgical outpatient clinic with a two-year history of right painful sciatica at the dorsal aspect of the right foot with coexisting affected limb soreness and clumsiness, which was compatible with a right L5 dermatome, and worsened over the last two months, necessitating the prescription of nonsteroidal antiinflammatory drugs (NSAIDs).

Her neurological presentation further aggravated to become an intractable right buttock pain accompanied with lower limb weakness, and she was even referred to the emergency department because of an inevitable injury due to an accidental fall that occurred as a consequence of her unsteady gait. Careful assessments revealed a positive straight leg raising test on the right at 70 degree; however, this test was negative on the left. On laboratory examination, patient's complete blood count, C-reactive protein, and urinalysis were normal. Biochemistry reports including uric acid $(4.1 \mathrm{mg} / \mathrm{dL})$ and electrolytes were all within normal ranges. Plain radiographs showed neither bony fracture over her

Table I Summary of Reported Cases of Lumbar Intraspinal CPPD

\begin{tabular}{|c|c|c|c|c|c|c|c|c|}
\hline Author(s) & Year & $\begin{array}{l}\text { Agel } \\
\text { Gender }\end{array}$ & $\begin{array}{l}\text { Radiological } \\
\text { Location }\end{array}$ & $\begin{array}{l}\text { Clinical Features/ } \\
\text { Duration }\end{array}$ & $\begin{array}{l}\text { Peripheral } \\
\text { Joint } \\
\text { Involvement }\end{array}$ & Treatment & $\begin{array}{l}\text { Case } \\
\text { Number }\end{array}$ & $\begin{array}{l}\text { Total } \\
\text { Number }\end{array}$ \\
\hline $\begin{array}{l}\text { Brown } \\
\text { et } \mathrm{al}^{23}\end{array}$ & $199 \mid$ & $\begin{array}{l}\text { Mean } \\
66.2 / \\
\text { unknown }\end{array}$ & $\begin{array}{l}\text { L3-4 (2), L4-5 (I) } \\
\text { ligamentum } \\
\text { flavum }\end{array}$ & $\begin{array}{l}\text { LBP }(2) \text {, left sciatica (I)/ } \\
\text { unknown }\end{array}$ & Unknown & Laminectomy & 3 & 3 \\
\hline $\begin{array}{l}\text { Salcman } \\
\text { et } \mathrm{al}^{24}\end{array}$ & 1994 & $50 / F$ & $\begin{array}{l}\text { Left L4-5 disc } \\
\text { space }\end{array}$ & $\begin{array}{l}\text { LBP, left sciatica/ } \\
\text { unknown }\end{array}$ & Unknown & $\begin{array}{l}\text { Hemi- } \\
\text { laminotomy }\end{array}$ & I & 4 \\
\hline Baty et $\mathrm{al}^{25}$ & 2003 & $39 / F$ & LI-2 disc space & LBP/ I month & Absent & $\begin{array}{l}\text { Decompression } \\
\text { and fusion }\end{array}$ & I & 5 \\
\hline Lam et $\mathrm{al}^{26}$ & 2007 & $\begin{array}{l}79 / F \\
72 / F\end{array}$ & $\begin{array}{l}\text { L3-4 ligamentum } \\
\text { flavum, L4-5 } \\
\text { epidural space }\end{array}$ & $\begin{array}{l}\text { LBP, both limbs } \\
\text { numbness/ } 2 \text { weeks } \\
\text { bilateral limbs } \\
\text { numbness/ I year }\end{array}$ & Unknown & Laminectomy & 2 & 7 \\
\hline $\begin{array}{l}\text { Mikhael } \\
\text { et } \mathrm{al}^{27}\end{array}$ & 2013 & $60 / M$ & L5-SI disc space & $\begin{array}{l}\text { LBP, bilateral sciatica/ } 2 \\
\text { months }\end{array}$ & Absent & $\begin{array}{l}\text { Decompression } \\
\text { and fusion }\end{array}$ & I & 8 \\
\hline $\begin{array}{l}\text { Cacciotti } \\
\text { et } \mathrm{al}^{28,} \dagger\end{array}$ & 2013 & $50 / \mathrm{F}$ & $\begin{array}{l}\text { L3-L4 intradural } \\
\text { space }\end{array}$ & $\begin{array}{l}\text { Both legs progressive } \\
\text { weakness and } \\
\text { claudication/ } 14 \text { years }\end{array}$ & Present & Laminectomy & I & 9 \\
\hline $\begin{array}{l}\text { Grobost } \\
\text { et } \mathrm{al}^{29}\end{array}$ & 2014 & $85 / M$ & $\begin{array}{l}\text { L4-5 epidural } \\
\text { space }\end{array}$ & LBP/ 4 years & Present & $\begin{array}{l}\text { Colchicine } \\
\text { therapy }\end{array}$ & I & 10 \\
\hline Greca et $\mathrm{a}^{30}$ & 2020 & $80 / F$ & $\begin{array}{l}\text { L4-5 ventral } \\
\text { epidural space }\end{array}$ & $\begin{array}{l}\text { LBP, left buttock and leg } \\
\text { numbness/ } 6 \text { months }\end{array}$ & Present & $\begin{array}{l}\text { Image-guided } \\
\text { biopsy and } \\
\text { aspiration }\end{array}$ & I & 11 \\
\hline $\begin{array}{l}\text { Chakravorty } \\
\text { et al }{ }^{31,+}\end{array}$ & 2021 & $81 / M$ & $\begin{array}{l}\mathrm{LI} \text { intradural } \\
\text { extramedullary }\end{array}$ & $\begin{array}{l}\text { LBP, both feet } \\
\text { numbness/ } 40 \text { years }\end{array}$ & Unknown & Laminectomy & I & 12 \\
\hline
\end{tabular}

Notes: ${ }^{\dagger}$ Cases of intradural CPPD.

Abbreviations: $M$, male; F, female; LBP, low back pain. 


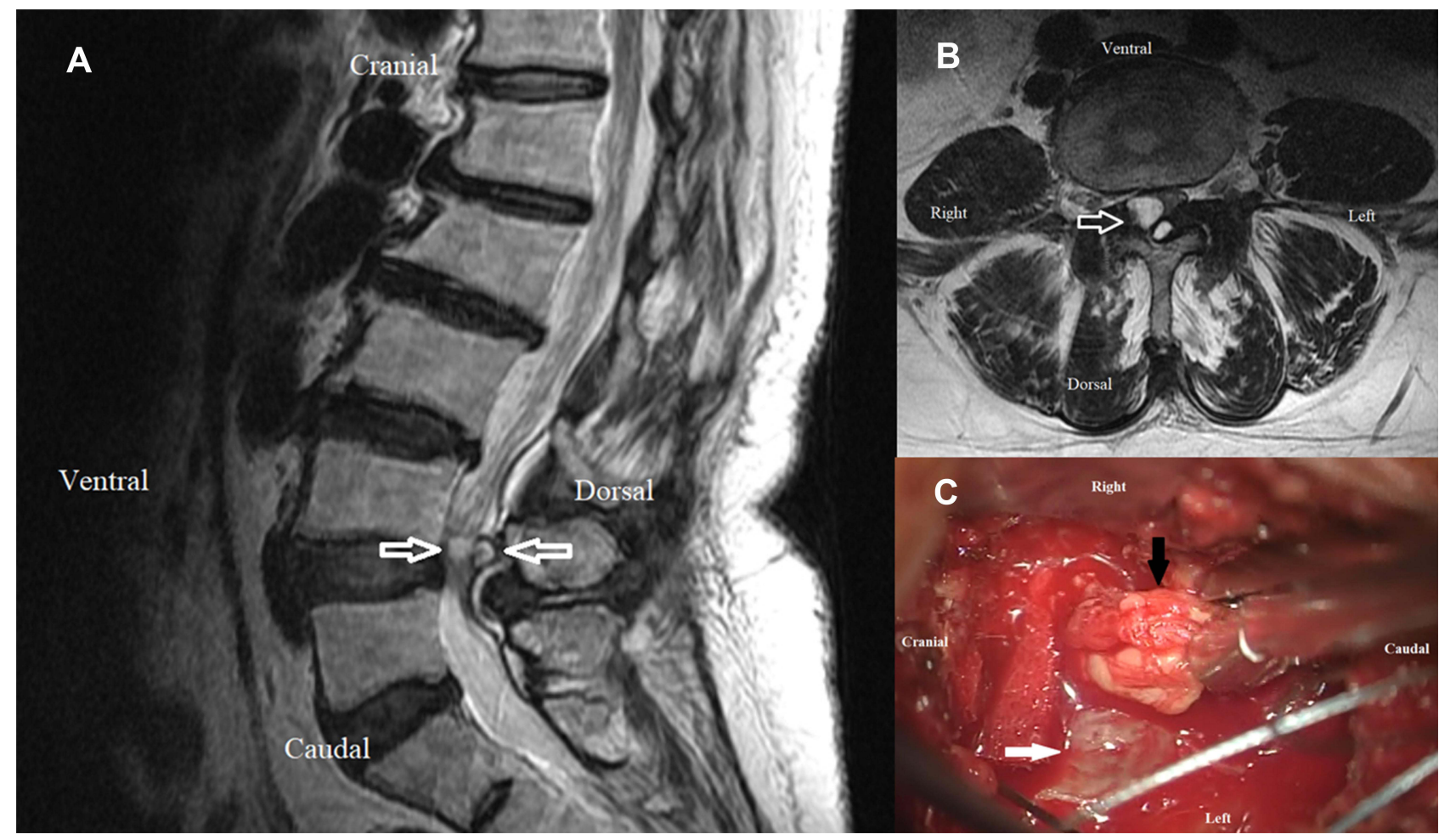

Figure I T2 weighted magnetic resonance imaging of the lumbar spine: coupled extradural cystic high intensity tumors on sagittal view (A) and axial view (B). Arrows demonstrating displacement of the L4-5 thecal sac and cauda equina with an extension into the corresponding right neuroforamen. Intraoperative photograph (C) showing the extradural tumor (black arrow) located at the right side of the dural sac (white arrow).

right hip nor the pathognomonic chondrocalcinosis of the lumbar spine. Axial-sagittal magnetic resonance imaging (MRI) revealed extradural cystic tumors causing moderate indentation and displacement of the L4-5 thecal sac and cauda equina, together with an extension into the corresponding right neuroforamen (Figure 1A and B). The lesion showed in the MRI was low intensity on T1 weighted and high intensity on T2 weighted, which implied a fluidic content. Further gadolinium enhanced survey revealed a weak rim enhancement of the structure.

A posterior laminectomy approach for tumor removal was then arranged. One main huge tumor was identified around the right L4-5 juxta-facet joint while the other minor was part beneath the spinal lamina. All tumors were excised intraoperatively with preservation of the neural structures. The masses were macroscopically extradural, tophaceous, and soft (Figure 1C). Microscopically, the specimen consisted of countless weakly positive birefringent rhomboid shaped crystals when examined under polarized light (Figure 2A and B). Her symptoms were relieved, and she experienced adequate functional recovery after the operation without recurrence for four years till now.

\section{Discussion}

Patients with CPPD could be characterized by a featured pattern in roentgenography, which exhibits as a highdensity linear structure within cartilage known as "chondrocalcinosis". 6,7 Although chondrocalcinosis is usually shown as a characteristic radiological finding, it can also be seen occasionally in ultrasonography. ${ }^{7}$ Even so, when we find calcification within cartilage, $40 \%$ of the patients have concomitant clinically active CPPD disease. ${ }^{8}$ On the other hand, chondrocalcinosis is not all composite of CPP crystals; some patients present with other non-CPP minerals, such as basic calcium phosphate (BCP). ${ }^{9} \mathrm{BCP}$ crystals encompass three different types of calcium crystals, such as carbonate-substituted hydroxyapatite, octacalcium phosphate, and tricalcium phosphate. Besides, BCP crystals usually produce coin-like calcifications around cartilage. In addition, BCP deposition is too small to be seen in roentgenogram. Finally yet importantly, depositional disease could present as mixed-type deposition from different minerals.

It is unusual to find intraspinal cysts in the lumbar spine. Ganglion cysts appeared more likely in the intraspinal extradural space adjacent to the facet joints. ${ }^{10}$ In our 


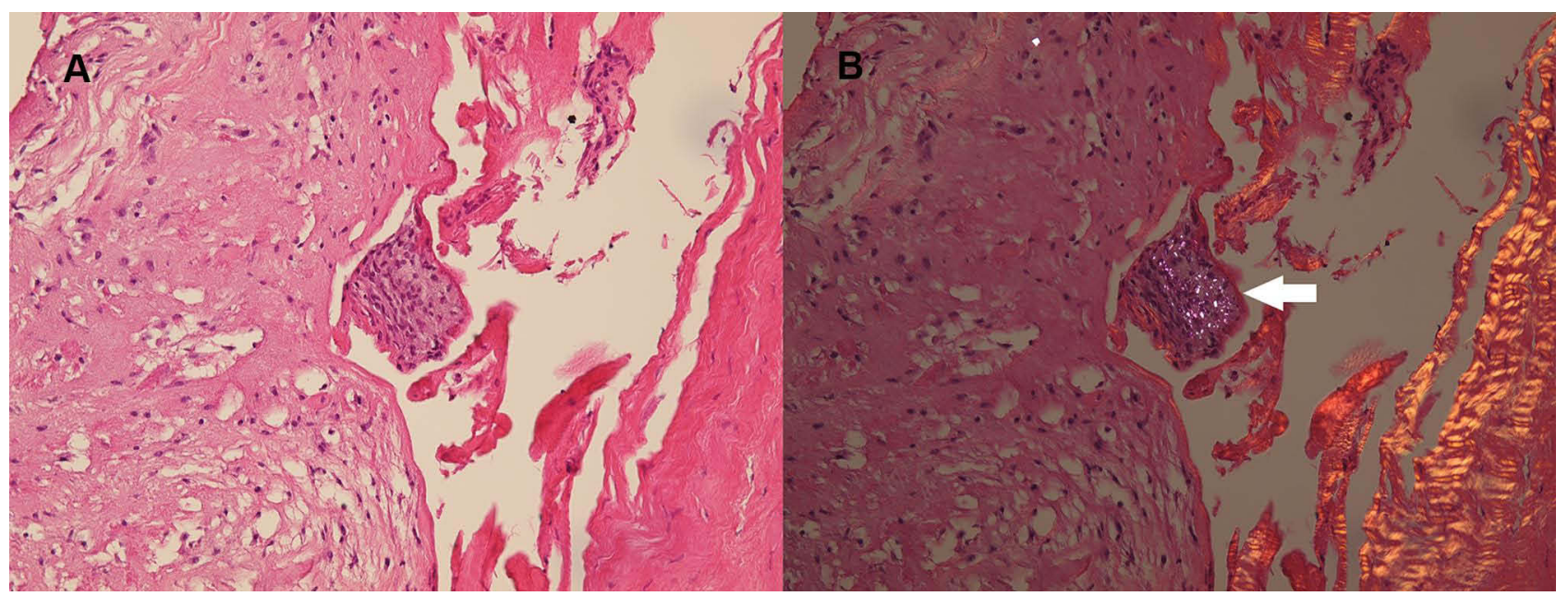

Figure 2 Histopathological photomicrograph: hematoxylin-eosin stain, magnification $\times 200($ A) and hematoxylin-eosin stain with polarization gating, magnification $\times 200($ B) showing numerous pathognomonic positively birefringent rhomboidal crystals (white arrow).

case, the cysts occurred at the level of L4-5 in the spinal canal just about the facet joint, as displayed clearly by MRI and confirmed by a radiologist. Eventually, surgical neural structures decompression in addition to cystic content extirpation demonstrated short diamond crystals that are blue in color under polarized light for the final accurate diagnosis. ${ }^{11}$

In addition to using microscopes, chest radiographs could also be used to distinguish between gout and CPPD. Konstantinos Parperis pointed out that chondrocalcinosis in the acromioclavicular (AC) joint on chest radiographs is associated with CPPD. Patients with AC joint chondrocalcinosis are more likely to have a history of CPPD crystals than patients without AC joint chondrocalcinosis. ${ }^{12}$ Christie M. Bartels even proposed the use of $\mathrm{A} / \mathrm{B} / \mathrm{C}$ categories to establish diagnostic criteria for CPPD disease. ${ }^{13}$

Pseudogout could sometimes mimic spinal tumors or hematomas. ${ }^{14,15}$ Spinal tumor is generally categorized into three groups; namely extradural tumor, intradural extramedullary tumor, and intradural intramedullary tumor. ${ }^{16}$ Extradural tumors are located outside the dura, which is the thin covering surrounding the spinal cord. The probability of tumor development in this location is approximately more than half that of the others. ${ }^{17}$ These are most commonly due to metastatic cancer. ${ }^{16}$ The representative pattern of malignancy might express multifocal lytic lesions identified by low signals on T1 and high signals on T2 weighted MRI with rim enhancement. Benign tumors should also be considered as a differential diagnosis that includes arachnoid cysts, vertebral hemangioma, or osteoblastoma that may be clinically expressed as local tenderness, limb sensitivity, and motor impairment. ${ }^{16}$

There are no effective medical measures to prevent CPP crystal accumulation in tissues or to eliminate them because much of the pathogenesis of CPPD deposition remains unclear. Oral colchicine tablets, NSAIDs, and local steroid injections may help control the symptoms. Chollet-Janin and colleagues reported that using 5-10mg of methotrexate (MTX) weekly could improve chronic CPPD. ${ }^{18}$ Pascual's laboratory also suggested that MTX might be beneficial for older patients with seronegative symmetrical polyarthritis showing chondrocalcinosis or CPP crystals. ${ }^{19}$ CPP and uric crystals can activate NLRP3 inflammasome, therefore promoting IL-1 $\beta$ secretion. Hence, IL-1 $\beta$ inhibitors may be used in treating CPP patients. Anakinra is an example of an IL- $1 \beta$ inhibitor, which has a good response in acute gouty attacks and could be chosen to treat CPPD in selected cases. ${ }^{20,21}$ Another drug known as Tocilizumab is an immunosuppressive remedy that acts on the interleukin- 6 receptor (IL-6R) to antagonize humanized monoclonal antibodies. This novel medication is often the recipe for rheumatoid arthritis (RA) and systemic juvenile idiopathic arthritis. It appears to be another efficacious and useful option in the treatment of CPPD. ${ }^{22}$

\section{Conclusion}

Spinal extradural tumor with rim enhancement has overlapped arguments as delineated in our report. The radiographical MRI in the current case showed one large cyst 
and a smaller one behind the other. We present the rare occurrence of pseudogout mimicking lumbar juxta-facet cysts preoperatively. We recommend surgical decompression in symptomatic cases accompanied by nerve root and/ or thecal sac compression. This case report raises awareness of CPPD as a cause of axial symptoms. The discovery of chondrocalcinosis should raise the suspicion of pseudogout or secondary osteoarthritis in an appropriate clinical setting. Additionally, in young patients, clinicians should be reminded of the possibility of related metabolic diseases.

\section{Ethical Approval}

Written informed consent for publication has been obtained from the patient. Approval from the institutional of Taipei Tzu Chi Hospital, Buddhist Tzu Chi Medical Foundation review board and ethics committee was obtained for the study (Protocol No.: 10-CR-015).

\section{Funding}

There is no funding to report.

\section{Disclosure}

The authors report no conflicts of interest in this work.

\section{References}

1. Rosales-Alexander JL, Balsalobre Aznar J, Magro-Checa C. Calcium pyrophosphate crystal deposition disease: diagnosis and treatment. Open Access Rheumatol. 2014;6:39-47. doi:10.2147/OARRR.S39039

2. Zhang W, Doherty M, Bardin T, et al. European league against rheumatism recommendations for calcium pyrophosphate deposition. Part I: terminology and diagnosis. Ann Rheum Dis. 2011;70(4):563-570. doi:10.1136/ard.2010.139105

3. Rosenthal AK, Ryan LM. Calcium pyrophosphate deposition disease. $N$ Engl J Med. 2016;374(26):2575-2584. doi:10.1056/ NEJMra1511117

4. Pascual E, Sivera F, Andrés M. Synovial fluid analysis for crystals. Curr Opin Rheumatol. 2011;23(2):161-169. doi:10.1097/ BOR.0b013e328343e458

5. Zell M, Zhang D, FitzGerald J. Diagnostic advances in synovial fluid analysis and radiographic identification for crystalline arthritis. Curr Opin Rheumatol. 2019;31(2):134-143. doi:10.1097 BOR.0000000000000582

6. Kohn NN, Hughes RE, Mc CD Jr., Faires JS. The significance of calcium phosphate crystals in the synovial fluid of arthritic patients: the "pseudogout syndrome". II. Identification of crystals. Ann Intern Med. 1962;56(5_Part_1):738-745. doi:10.7326/0003-4819-56-5-738

7. Halupa AJ, Strony RJ, Bulbin DH, Kraus CK. Pseudogout diagnosed by point-of-care ultrasound. Clin Pract Cases Emerg Med. 2019;3 (4):425-427. doi:10.5811/cpcem.2019.7.43244

8. Fuerst M, Bertrand J, Lammers L, et al. Calcification of articular cartilage in human osteoarthritis. Arthritis Rheum. 2009;60 (9):2694-2703. doi:10.1002/art.24774

9. Rosenthal AK. Basic calcium phosphate crystal-associated musculoskeletal syndromes: an update. Curr Opin Rheumatol. 2018;30 (2):168-172. doi:10.1097/BOR.0000000000000477
10. Tai PA, Li TC. Lumbar intradural ganglion cyst. World Neurosurg. 2016;88:691.e691-691.e694. doi:10.1016/j.wneu.2015.11.088

11. Biankin S, Jaworski R, Mawad S. Tumoural calcium pyrophosphate dihydrate crystal deposition disease presenting clinically as a malignant soft tissue mass diagnosed on fine needle aspiration biopsy. Pathology. 2002;34(4):336-338. doi:10.1080/ 003130202760120490

12. Parperis K, Carrera G, Baynes K, et al. The prevalence of chondrocalcinosis (CC) of the acromioclavicular (AC) joint on chest radiographs and correlation with calcium pyrophosphate dihydrate (CPPD) crystal deposition disease. Clin Rheumatol. 2013;32(9):1383-1386. doi:10.1007/s10067-013-2255-x

13. Bartels CM, Singh JA, Parperis K, Huber K, Rosenthal AK. Validation of administrative codes for calcium pyrophosphate deposition: a veterans administration study. J Clin Rheumatol. 2015;21 (4):189-192. doi:10.1097/RHU.0000000000000251

14. Kishore B, Khare P, Gupta RJ, Gupta C, Khare V. Tumoral calcium pyrophosphate dihydrate crystal deposition disease: a rare diagnosis by fine-needle aspiration. Diagn Cytopathol. 2010;38(1):47-50. doi: $10.1002 / \mathrm{dc} .21155$

15. deSouza RM, Uff C, Galloway M, Dorward NL. Spinal epidural hematoma caused by pseudogout: a case report and literature review. Global Spine J. 2014;4(2):105-108. doi:10.1055/s-00331360722

16. Van Goethem JW, van den Hauwe L, Ozsarlak O, De Schepper AM, Parizel PM. Spinal tumors. Eur J Radiol. 2004;50(2):159-176. doi:10.1016/j.ejrad.2003.10.021

17. Reith W, Yilmaz U. [Extradural tumors]. Radiologe. 2011;51 (12):1018-1024. doi:10.1007/s00117-011-2152-8 [French]

18. Chollet-Janin A, Finckh A, Dudler J, Guerne PA. Methotrexate as an alternative therapy for chronic calcium pyrophosphate deposition disease: an exploratory analysis. Arthritis Rheum. 2007;56 (2):688-692. doi:10.1002/art.22389

19. Pascual E, Andrés M, Sivera F. Methotrexate: should it still be considered for chronic calcium pyrophosphate crystal disease? Arthritis Res Ther. 2015;17(1):89. doi:10.1186/s13075-015-0598-1

20. Sivera F, Andrés M, Pascual E. Current advances in therapies for calcium pyrophosphate crystal arthritis. Curr Opin Rheumatol. 2016;28(2):140-144. doi:10.1097/BOR.0000000000000252

21. Campillo-Gimenez L, Renaudin F, Jalabert M, et al. Inflammatory potential of four different phases of calcium pyrophosphate relies on NF- $\mathrm{B}$ activation and MAPK pathways. Front Immunol. 2018;9:2248. doi:10.3389/fimmu.2018.02248

22. Parperis K, Papachristodoulou E, Kakoullis L, Rosenthal AK. Management of calcium pyrophosphate crystal deposition disease: a systematic review. Semin Arthritis Rheum. 2021;51(1):84-94. doi:10.1016/j.semarthrit.2020.10.005

23. Brown TR, Quinn SF, D'Agostino AN. Deposition of calcium pyrophosphate dihydrate crystals in the ligamentum flavum: evaluation with MR imaging and CT. Radiology. 1991;178(3):871-873. doi:10.1148/radiology.178.3.1994435

24. Salcman M, Khan A, Symonds DA. Calcium pyrophosphate arthropathy of the spine: case report and review of the literature. Neurosurgery. 1994;34(5):915-918; discussion 918. doi:10.1227/ 00006123-199405000-00022

25. Baty V, Prost B, Jouvet A, Laurent J, Vallée B. Acute spinal cord compression and calcium pyrophosphate deposition disease. Case illustration. J Neurosurg. 2003;99(2 Suppl):240. doi:10.3171/ spi.2003.99.2.0240

26. Lam HY, Cheung KY, Law SW, Fung KY. Crystal arthropathy of the lumbar spine: a report of 4 cases. J Orthop Surg (Hong Kong). 2007;15(1):94-101. doi:10.1177/230949900701500122

27. Mikhael MM, Chioffe MA, Shapiro GS. Calcium pyrophosphate dihydrate crystal deposition disease (pseudogout) of lumbar spine mimicking osteomyelitis-discitis with epidural phlegmon. $A m$ J Orthop (Belle Mead NJ). 2013;42(8):E64-67. 
28. Cacciotti G, Novegno F, Fiume D. Calcium pyrophosphate dihydrate deposition disease of the filum terminale. Eur Spine J. 2013;22 Suppl 3(Suppl 3):S501-505. doi:10.1007/s00586-013-2723-7

29. Grobost V, Vayssade M, Roche A, Kemeny JL, Soubrier M. Axial calcium pyrophosphate dihydrate deposition disease revealed by recurrent sterile spondylodiscitis and epidural abscess. Joint Bone Spine. 2014;81(2):180-182. doi:10.1016/j.jbspin.2013.07.007
30. Greca I, Ben Gabr J, Perl A, Bryant S, Zaccarini D. Trauma induced calcium pyrophosphate deposition disease of the lumbar spine. Case Rep Rheumatol. 2020;2020:3218350. doi:10.1155/2020/3218350

31. Chakravorty A, Murambi RT, Cherukuri RKV. Intradural calcium pyrophosphate dihydrate deposition disease: case report. $J$ Neurosurg Spine. 2021;1-4. doi:10.3171/2020.9.SPINE201010

\section{Publish your work in this journal}

The Journal of Multidisciplinary Healthcare is an international, peerreviewed open-access journal that aims to represent and publish research in healthcare areas delivered by practitioners of different disciplines. This includes studies and reviews conducted by multidisciplinary teams as well as research which evaluates the results or conduct of such teams or healthcare processes in general. The journal covers a very wide range of areas and welcomes submissions from practitioners at all levels, from all over the world. The manuscript management system is completely online and includes a very quick and fair peer-review system. Visit http://www.dovepress.com/testimonials. php to read real quotes from published authors. 